\title{
Intraoperative navigation system for ventriculoperitoneal shunting improves outcomes in patients with hydrocephalus compared with conventional procedures via the occipital horn
}

\author{
Aijun Peng \\ West China Hospital, Sichuan University \\ Hai Zhao \\ West China Hospital, Sichuan University \\ Yongkang Wu \\ the Affiliated Hospital of Yangzhou University \\ Yi Zhao \\ the Affiliated Hospital of Yangzhou University \\ Liangxue Zhou ( $\square$ zhlxsch@163.com ) \\ West China Hospital of Sichuan University
}

\section{Research article}

Keywords: Hydrocephalus, Ventriculoperitoneal shunt, Intraoperative navigation, Ventricle catheter obstruction

Posted Date: June 3rd, 2019

DOI: https://doi.org/10.21203/rs.2.10049/v1

License: (c) (i) This work is licensed under a Creative Commons Attribution 4.0 International License. Read Full License

Version of Record: A version of this preprint was published at British Journal of Neurosurgery on July 15 th, 2020. See the published version at https://doi.org/10.1080/02688697.2020.1789555. 


\section{Abstract}

Background: Ventriculoperitoneal shunting (VPS) is a common neurosurgical procedure for treating hydrocephalus. Catheter obstruction is one of the most common factors influencing patient prognosis. We evaluated the possibility of improving the accuracy of proximal catheter placement and the probable relationship of ventricular catheter obstruction with the symptom grade and postoperative Evans index with intraoperative navigation for VPS compared with conventional surgery via the occipital horn. Method: We performed a retrospective study including 33 patients with VPS in the navigation surgery group and 26 patients with VPS in the conventional surgery group between January 2012 and August 2018. The clinical data, follow-up time, catheterization accuracy, postoperative outcomes, cumulative survival time and correlations of catheter placement with obstruction and of catheter obstruction with the symptom grade and postoperative Evans index were analyzed. Results: Thirty-one patients experienced optimal ventricular catheter placement (grade 1), 2 patients experienced suboptimal placement (grade 2), and no patients experienced poor ventricular catheter placement (grade 3 ) in the navigation surgery group compared with 6, 14, and 6 patients, respectively, in the conventional surgery group. Greater improvement in postoperative symptoms $(\mathrm{P}=0.017)$ was observed in the navigation surgery group, including less catheter readjustment $(P<0.001)$. Kaplan-Meier survival analysis showed that the cumulative catheter obstruction-free survival time was longer in the navigation surgery group than in the conventional surgery group $(P=0.028)$. Catheter placement was significantly correlated with catheter obstruction $(P<0.001)$. In addition, catheter obstruction was significantly correlated with the symptom grade $(P=0.001)$ and postoperative Evans index $(P<0.001)$ Conclusions: The intraoperative navigation system for VPS improved patient outcomes and the accuracy of ventricular catheter placement. Catheter obstruction-free survival time was longer in the navigation surgery group, and catheter placement was significantly correlated with catheter obstruction.

\section{Background}

Ventriculoperitoneal shunting (VPS) continues to be the most important surgical treatment for patients with hydrocephalus; these patients typically exhibit gait disturbance, cognitive impairment and urinary incontinence and show enlarged ventricles on computed tomography (CT) or magnetic resonance imaging (MRI). Previous studies[ 1-3] have reported that treatment for patients with hydrocephalus who require cerebrospinal fluid (CSF) diversion can cost millions of dollars[ 4,5$]$, which presents a significant burden to society.

Although patients with hydrocephalus significantly benefit from VPS, complications are unavoidable and influence the long-term survival of these patients. Some studies[ 6-9] demonstrated that catheter obstruction may be the most common cause of shunt failure. Even experts who perform VPS according to cranial landmarks have certain misplacement rates. Proximal catheters with poor positioning are associated with a greater risk for catheter blockage[ 10, 11], which may require another surgery for catheter adjustment, inducing additional suffering for patients and contributing to financial and social burdens for families. Therefore, a navigation system for VPS is necessary to decrease these complication rates.

Although previous studies $[10,12]$ have reported the superiority of using a navigation system in VPS compared with conventional surgery, the probable relationships among clinical symptoms, ventricular catheter placement, catheter obstruction and postoperative Evans index have not been clearly reported. In this study, we reviewed patients with hydrocephalus undergoing intraoperative navigation surgery to evaluate the possibility of improving the accuracy of proximal catheter placement and the probable relationships of ventricular catheter obstruction with the symptom grade and postoperative Evans index.

\section{Methods}




\section{Demographic data}

This study retrospectively reviewed a series of 59 patients with hydrocephalus for VPS in the neurosurgery department of the Affiliated Hospital of Yangzhou University, Jiangsu, China, between January 2012 and August 2018. According to the surgeon's preference, thirty-three patients were included in the navigation surgery group, and 26 patients were included in the conventional surgery group, in which surgeons only took advantage of cranial anatomical landmarks.

The inclusion criteria for surgery were as follows: (1) The patient exhibited clinical symptoms, including gait disturbance, cognitive impairment or urinary incontinence. (2) The imaging examinations demonstrated that the ventricle was enlarged with edema along its wall. (3) The lumbar puncture (LP) tap test was positive. (4) The characteristics of CSF were normal. Patients with previous shunt failures caused by dysfunction or distal failure, obstructive hydrocephalus or who had previously undergone neuroendoscopic surgery were excluded.

All patients at admission were evaluated for the severity of symptoms according to their symptom grading[13] and underwent thin-slice CT (Siemens, Germany) or MRI (Siemens, 3.0T) examinations (scans ranged from the upper lip, including the apex nasi region to the parietal region, slice thickness: $1 \mathrm{~mm}$ ) before surgery. LP was performed for all patients with the tap test to measure ICP and CSF parameters, including protein concentration and red blood cell population. VPS equipment, including a ventricular catheter, a peritoneal catheter and a programmable antisiphon valve (Strata $₫$ Valve, Regular, Medtronic, USA), was used.

\section{Preoperative planning and operation procedure}

In the navigation surgery group, imaging data based on preoperative CT or MR scans of patients were stored on CDROMs, which were uploaded into the navigation system (StealthStation S7 Fusion, Medtronic, USA). Then, the target point, entry point, trajectory and depth of insertion were planned using the navigation software before surgery (Fig. 1). The navigation reference antenna was fixed to the Mayfield holder, which was used to fix the patient's head. After successful registration with the trace approach, calibration according to maxillofacial surface landmarks was performed to examine the accuracy error, controlling the accuracy error to within $2 \mathrm{~mm}$. Navigation was then performed to find the entry point according to the preoperative routine in advance. Furthermore, the entry point should be checked again via intraoperative navigation before removing the skull with a milling cutter (Medtronic, USA). After cutting the dura, the ventricle catheter with the navigation tracker was adjusted to the expected position in accordance with preoperative planning for connection to the programmable valve. Next, a 4- to 5-cm middle incision in the upper abdomen was made, dividing the subcutaneous tissue and cutting the sheath of the rectus abdominis and the peritoneum to obtain access to the peritoneal cavity. Before placing the peritoneal catheter in the superior region of the liver, the CSF flow should be confirmed with smoothing from the proximal catheter tip.

In the conventional group, Frazier's point on the right side was usually selected as the entry point. The insertion length was generally 8-10 $\mathrm{cm}$ through the occipital horn. The rest of the operation procedure was the same as that in the navigation group. All operations were performed by senior neurosurgeons.

\section{Outcome measurements}

In the present study, the severity of symptoms according to the grade systems [13] was evaluated before (at admission) and after surgery (at 6 months after surgery). The etiology of hydrocephalus, the CSF parameters, catheterization accuracy, and operation time, some complications, the follow-up time and the catheter obstruction-free survival time after surgery were also evaluated. Ventricular catheter placement was assessed based on the grade system[12]. The 
correlation between ventricular catheter placement and catheter obstruction was analyzed, as were the correlations between catheter obstruction and the symptom grade and postoperative Evans index. All patients underwent CT scans during the $1^{\text {st }}$ day after surgery to determine the position of the ventricular catheter and to rule out bleeding. The first follow-up was within 1 month of discharge, and subsequent follow-ups were within 3 months, 6 months, 12 months, 24 months and 48 months. The follow-up evaluations included the patient's symptoms and imaging examinations according to the variation in the patient's symptoms.

\section{Statistical analysis}

Statistical analyses were performed using SPSS v.23.0 (Armonk, New York, United States). Independent t tests were used to compare continuous variables, which are expressed as the mean \pm standard deviation. Differences in the depth and grade of ventricular catheter placement in the navigation surgery group between the preoperative plan and postoperative results were analyzed by paired t test. Categorical variables in these 2 groups were compared by the Mann-Whitney test. The correlations between catheter obstruction and postoperative Evans index and symptom grade as well as those between proximal catheter placement and catheter obstruction were evaluated by Pearson correlation analysis. The cumulative catheter obstruction-free survival was calculated by Kaplan-Meier survival statistics.

\section{Results}

\section{Clinical characteristics between the navigation surgery group and the conventional surgery group}

The mean ages of patients were 56.18 years (ranging from 21 to 78 years) in the navigation surgery group and 58.73 years (ranging from 23 to 73 years) in the conventional surgery group. In this study, the most common causes of hydrocephalus in the navigation surgery group were cerebrovascular diseases (48.48\%), followed by head trauma (27.27\%), which were also the most common causes of hydrocephalus in the conventional surgery group, corresponding to $46.15 \%, 38.46 \%$, respectively (Table 2 ). There were no significant differences, including in the preoperative Evans index and CSF characteristics, in these 2 groups preoperatively (Table 2).

\section{Accuracy and precision of ventricular catheterization in the navigation surgery group}

In the preoperative plan in the navigation group, the mean depth of the ventricular catheter and the grade of catheter placement according to the navigation system were not significantly different from those determined by postoperative CT (Table 3).

\section{Postoperative outcomes of the 2 groups}

In the navigation surgery group, compared with preoperative symptoms, the postsurgical symptoms after VPS, as presented in Table 4, were significantly improved $(\mathrm{P}<0.001)$ six months after surgery, while there was no significant difference in the conventional surgery group $(\mathrm{P}=0.096)$. In addition, the clinical symptoms greatly improved six months after surgery in the navigation group compared with the conventional surgery group $(P=0.017)$. Through the preoperative planning (Fig. 1), the postoperative CT revealed the optimal ventricular catheter placement in VPS (Fig. 2). The total patient numbers for each grade of ventricular catheter placement in the 2 groups are presented in Fig. 3. 
Nine patients (34.62\%) in the conventional surgery group and 3 patients $(9.09 \%)$ in the navigation surgery group developed ventricular catheter obstruction $(P<0.001$, Table 5). According to the correlation analysis, catheter obstruction was significantly correlated with the symptom grade and postoperative Evans index (Fig. 4). In addition, ventricular catheter placement had a significant correlation with catheter obstruction $(P<0.001$, Table 6$)$. Detailed characteristics of the cases of ventricular catheter obstruction are described in Table 7.

Additionally, the average total operative times (from skin incision to skin closure) were 64.00 minutes with a range of 5575 minutes in the navigation surgery group and 77.77 minutes with a range of 65-89 minutes in the conventional surgery group $(\mathrm{P}<0.001)$. The postoperative Evans index and ventricular catheter obstruction were also significantly different between the two groups $(P<0.001)$, although infection $(P=0.264)$ and bleeding $(P=0.264)$ after surgery did not significantly differ between groups (Table 5).

\section{Catheter obstruction-free survival after VPS}

The mean follow-up times were 19.15 months with a range of 1-36 months in the navigation surgery group and 18.46 months with a range of 1-38 months in the conventional surgery group (Fig. 5), which were not significantly different $(P=0.760$, Table 5). Furthermore, the Kaplan-Meier survival analysis of catheter obstruction-free survival after VPS within the follow-up time period is presented in Fig. 6. The Kaplan-Meier survival analysis indicated that the cumulative obstruction-free survival time of the catheter in the navigation surgery group was longer than that in the conventional surgery group. The initial slope was much steeper in the conventional surgery group than in the navigation surgery group, which indicated early catheter obstruction in the conventional surgery group $(P=0.028$, Table 8$)$.

\section{Discussion}

In this report, we demonstrate that VPS for hydrocephalus via the occipital horn with a navigation system is superior to the conventional surgical procedure in terms of the clinical outcome, accuracy and precision of ventricular catheterization and complications. We report detailed characteristics of the cases of ventricular catheter obstruction. We found that catheter placement was significantly correlated with catheter obstruction. In addition, catheter obstruction was significantly correlated with symptom grade and postoperative Evans index. We also found that the cumulative catheter obstruction-free survival time was longer in the navigation surgery group than in the conventional surgery group.

Catheter placement into the lateral ventricle, remote from other structures, is common in VPS, as accurate placement of the ventricular catheter is very important for long-term catheter obstruction-free survival. Such accurate catheter placement may be more easily achieved with intraoperative navigation for VPS. Previous studies[ 11, 14-19] have reported the use of ultrasound, frameless stereotaxy, neuroendoscopy and navigation to increase the accuracy of ventricular catheter placement and to improve long-term outcomes for patients with hydrocephalus. A systematic review by Flannery[20] showed that there was insufficient evidence to recommend the use of neuroendoscopy for routine VPS. Additionally, a meta-analysis by Nesvick et al.[16] revealed that ultrasound and stereotaxy do not increase catheter placement accuracy and reported only a weak benefit for hydrocephalus. Yamada et al.[ 21 ] reported that 48 patients who underwent navigation surgery for VPS did not need shunt revision, but the effective rate was not reported due to loss of patients to follow-up. This study reported intraoperative navigation for patients with hydrocephalus with VPS and an approximately 36-month follow-up compared with conventional VPS.

Conventional VPS, which is based only on cranial anatomic landmarks and personal experience, is a relatively easy procedure, although misplaced proximal catheters are associated with negative side-effects and may be at greater risk for eventual blockage, making another shunt revision necessary. Yoon et al.[11] showed that 31.7\% of patients with suboptimal catheter placement may experience catheter obstruction. Using intraoperative fluoroscopic imaging, Janson 
et al.[10] showed that $43.9 \%$ of patients received optimal catheter placement, and $56.1 \%$ of patients received suboptimal or poor shunt placement with a $57 \%$ higher risk of shunt failure.

In this study, in the conventional VPS group, 14 patients (53.84\%) had suboptimal catheter placement, and 6 patients (23.08\%) had poor placement mainly because the direction of ventricular catheterization was skewed. Ultimately, 9 (34.62\%) patients had ventricular catheter obstruction, with a mean follow-up time of 18.46 months, which required catheter readjustment. Moreover, all patients with grade 3 catheter placement experienced catheter obstruction during the first year after surgery, and only one patient required 3 punctures (Table 7).

Intraoperative navigation for VPS, with its advantages of high accuracy and reliable preoperative planning using navigational software, can also increase the accuracy and precision of ventricular catheter placement. In this study, a programmable valve was selected for all patients, and the parameter of the programmable valve was initially set to 1.01.5 to avoid drainage, according to the ICP obtained by LP. In determining the insertion trajectory during preoperative planning, the target point must be far from the choroid plexus and the foramen. Additionally, successful ventricular catheter insertion with an accurate target point, a reliable trajectory, and real-time monitoring during the operation was achieved in all cases. In the navigation group, only 2 patients (6.06\%) received suboptimal placement, which was caused by too much CSF drainage during the operation, causing the brain to shift. Nimsky et al.[22] demonstrated that accuracy may be significantly compromised once brain shift occurs secondary to CSF drainage in the operation. However, the accuracy error was less than $2 \mathrm{~mm}$ according to a comparison of the depth of the inserted ventricular catheter on postoperative CT with the depth according to the navigational software in the preoperative planning.

Many neurosurgeons typically utilize the frontal horn approach and the occipital horn approach for VPS, though the optimal surgical approach remains controversial[10]. Previous studies have reported[10,21,23] that the success rate of the frontal approach via the freehand procedure ranges from 43.9-64\%. In addition, some studies[ 24, 25] have demonstrated that VPS via the frontal horn approach may increase the incidence of epilepsy in patients with hydrocephalus, especially in children with hydrocephalus. Through the occipital horn, the catheter can be advanced to the frontal horn far away from the choroid plexus. In addition, the occipital horn approach may be selected as the entry point in patients with hydrocephalus who undergo frontal-temporal decompression craniectomy, regardless of how difficult it is to palpate the external occipital protuberance. All of these factors make intraoperative navigation essential for occipital approaches of VPS.

The efficacy of VPS has been extensively studied by evaluating multiple factors, mainly clinical symptoms and radiological outcomes. Karimy et al.[26] mentioned that the mechanism of posthemorrhagic hydrocephalus may involve CSF hypersecretion. Benveniste et al.[27] reported that $80 \%$ of patients had objective improvement in hydrocephalus symptoms after VPS, although $49 \%$ of patients developed delayed deterioration of symptoms, probably due to shunt failure or underdrainage. In this study, in the navigation surgery group, the clinical symptoms of most patients improved greatly after VPS. Additionally, we found that ventricular catheter obstruction was significantly correlated with symptom grade $(P=0.001)$ and postoperative Evans index $(P<0.001$, Fig. 4$)$. A probable explanation may be that sufficient CSF drainage with accurate catheter placement results in symptomatic improvements and decreased ventricular size. However, due to the attrition in the clinical follow-up, a large population with appropriate follow-up durations may be necessary to determine the effectiveness of VPS.

Whether using navigation increases operation time remains controversial. Although the installation and registration require time, an experienced person can complete all of the operations quickly while intravenous anesthesia begins. Additionally, previous studies[ 12,28$]$ demonstrated that the additional time spent preparing for navigation did not exceed 15 minutes. Therefore, the extra time needed would not increase the overall procedure time. In this study, the operation time (from skin incision to skin closure) was shorter in the navigation surgery group than in the conventional surgery 
group due to the operation of skilled neurosurgeons and the individualized design of the surgical approach with the navigation application.

The most common complications of VPS were infection and shunt failure, leading to many hospital readmissions. In a review by Paf et al.[29], the infection rate was approximately $8-15 \%$ among patients who underwent VPS placement. In this study, there were no infections among patients in the navigation group, while only one patient (3.85\%) with 3 punctures during the operation developed an infection in the conventional group. Hayhurst[ 12] showed that $78 \%$ of standard shunts failed in the early stage, mainly due to proximal obstruction. Deckerman et al.[30] demonstrated that catheters placed farther from the choroid plexus were correlated with a lower rate of shunt failure at six months. In this study, 3 patients (9.09\%) developed catheter obstruction in the navigation surgery group, while $34.62 \%$ of patients developed catheter obstruction in the conventional surgery group. Due to location inaccuracy, the burr hole was made too close to the midline, causing slight damage to the superior sagittal sinus and a subsequent subdural hematoma through the occipital approach in one patient in the conventional surgery group.

A study presented by Jeremiah et al.[ 6] showed that poor catheter position was substantially more likely to require subsequent shunt revision by Kaplan-Meier survival analysis. Reddy[ 9] demonstrated that adult patients had significantly higher revision-free survival than pediatric patients after their first shunt surgery, and most shunt revisions occurred early, within six months. In this study, catheter obstruction-free survival was higher in the navigation surgery group than in the conventional surgery group $(\mathrm{P}=0.028)$. The Kaplan-Meier survival curve (Fig. 6) presumably indicated that catheter obstruction-free survival was related to intraoperative navigation during VPS. The initial slope was much steeper for the conventional surgery group than for the navigation surgery group, which demonstrated early catheter obstruction in the conventional surgery.

This study had certain limitations. First, this was a nonrandomized, single-center retrospective study with a small number of cases that did not include pediatric patients with hydrocephalus because few pediatric patients with hydrocephalus received VPS, and some patients had a negative CSF tap test or inadequate follow-up data. In addition, this study only included patients who underwent catheter insertion via the occipital horn; therefore, the possibility of selection bias due to the methodology cannot be ignored. Second, we did not have a way to randomize the choice of navigation for VPS. Third, there was not a sufficient number of samples to perform a multivariate analysis of all risk factors to predict the prognosis of patients with hydrocephalus and the long-term catheter obstruction-free survival, which should be further evaluated in a randomized controlled clinical trial. Therefore, a multicenter, prospective clinical trial based on a large population with appropriate follow-up durations may be necessary to determine the effectiveness of VPS, which may bring clear benefits to patients with hydrocephalus.

\section{Conclusions}

Our findings suggested that intraoperative navigation for VPS resulted in accurate and precise proximal catheter placement and improved symptoms in patients with hydrocephalus. We found that catheter obstruction was significantly correlated with symptom grade and postoperative Evans index. Additionally, ventricular catheter placement had significant correlations with catheter obstruction and the longevity of catheter obstruction-free survival in the navigation surgery group compared with the conventional surgery group.

\section{Abbreviations}

CSF: Cerebrospinal fluid; CT: Computed tomography; iNPH: Idiopathic normal pressure hydrocephalus; ICP: Intracranial pressure; LP: Lumbar puncture; MRI: Magnetic resonance imaging; NPH: Normal pressure hydrocephalus; VPS:

Ventriculoperitoneal shunting.

Page $7 / 18$ 


\section{Declarations}

\section{Ethics approval and consent to participate}

This study was approved by the ethics committee of West China Hospital, Sichuan University, China. Informed consent was obtained from all individual participants included in the study.

\section{Consent for publication}

The patient's family has consented to use of image and the submission of the article for submission to the journal.

\section{Availability of data and material}

The datasets generated and analysed during the current study are not publicly available due identifying patient data should not be shared but are available from the corresponding author on reasonable request.

\section{Competing interests}

The authors declare no conflicts of interest.

\section{Funding}

This study was funded by Sichuan Provincial Human Resources and Social Security Department (Grant Number 2016183-11) in collection, analysis and interpretation of data and in writing the manuscript.

\section{Authors' contributions}

P AJ, W YK and Z Y were involved in study design, data collection. The manuscript was written by P AJ. P AJ and Z H was responsible for the statistical analyses and interpretation of study results. $Z$ LX was the principal investigator for the study, contributed data and participated in data interpretation as well as in the development of the manuscript. All authors have made substantial contributions to this study and approved submission to this journal.

\section{Acknowledgements}

We thank the staffs of Neurosurgery department at Affiliated Hospital of Yangzhou University, who generously assisted the VPS in this study.

\section{References}

1. Dewan MC, Rattani A, Mekary R, Glancz LJ, Yunusa I, Baticulon RE, et al. Global hydrocephalus epidemiology and incidence: systematic review and meta-analysis. Journal of neurosurgery. 2018:1-15; doi: 10.3171/2017.10.JNS17439.

2. Brean A, Eide PK. Prevalence of probable idiopathic normal pressure hydrocephalus in a Norwegian population. Acta Neurol Scand. 2008;118 1:48-53; doi: 10.1111/j.1600-0404.2007.00982.x. 
3. Mori E, Ishikawa M, Kato T, Kazui H, Miyake H, Miyajima M, et al. Guidelines for management of idiopathic normal pressure hydrocephalus: second edition. Neurol Med Chir (Tokyo). 2012;52 11:775-809.

4. Simon TD, Riva-Cambrin J, Srivastava R, Bratton SL, Dean JM, Kestle JR, et al. Hospital care for children with hydrocephalus in the United States: utilization, charges, comorbidities, and deaths. J Neurosurg Pediatr. 2008;1 2:131-7; doi: 10.3171/PED/2008/1/2/131.

5. Patwardhan RV, Nanda A. Implanted ventricular shunts in the United States: the billion-dollar-a-year cost of hydrocephalus treatment. Neurosurgery. 2005;56 1:139-44; discussion 44-5.

6. Jeremiah KJ, Cherry CL, Wan KR, Toy JA, Wolfe R, Danks RA. Choice of valve type and poor ventricular catheter placement: Modifiable factors associated with ventriculoperitoneal shunt failure. Journal of clinical neuroscience : official journal of the Neurosurgical Society of Australasia. 2016;27:95-8; doi: 10.1016/j.jocn.2015.07.026.

7. Gilard V, Magne N, Gerardin E, Curey S, Pelletier V, Hannequin P, et al. Comparison of electromagnetic neuronavigation system and free-hand method for ventricular catheter placement in internal shunt. Clinical neurology and neurosurgery. 2017;158:93-7; doi: 10.1016/j.clineuro.2017.05.007.

8. Wan KR, Toy JA, Wolfe R, Danks A. Factors affecting the accuracy of ventricular catheter placement. Journal of clinical neuroscience : official journal of the Neurosurgical Society of Australasia. 2011;18 4:485-8; doi: 10.1016/j.jocn.2010.06.018.

9. Reddy GK, Bollam P, Caldito G. Long-term outcomes of ventriculoperitoneal shunt surgery in patients with hydrocephalus. World neurosurgery. 2014;81 2:404-10; doi: 10.1016/j.wneu.2013.01.096.

10. Janson CG, Romanova LG, Rudser KD, Haines SJ. Improvement in clinical outcomes following optimal targeting of brain ventricular catheters with intraoperative imaging. Journal of neurosurgery. 2014;120 3:684-96; doi: 10.3171/2013.8.JNS13250.

11. Yoon SY, Kwak Y, Park J. Adjustable Ghajar Guide Technique for Accurate Placement of Ventricular Catheters: A Pilot Study. J Korean Neurosurg Soc. 2017;60 5:604-9; doi: 10.3340/jkns.2016.1011.004.

12. Hayhurst $C$, Beems T, Jenkinson MD, Byrne P, Clark S, Kandasamy J, et al. Effect of electromagnetic-navigated shunt placement on failure rates: a prospective multicenter study Clinical article. Journal of neurosurgery. 2010;113 6:1273-8; doi: 10.3171/2010.3.Jns091237.

13. Krauss JK, Droste DW, Vach W, Regel JP, Orszagh M, Borremans JJ, et al. Cerebrospinal fluid shunting in idiopathic normal-pressure hydrocephalus of the elderly: effect of periventricular and deep white matter lesions. Neurosurgery. 1996;39 2:292-9; discussion 9-300.

14. Crowley RW, Dumont AS, Asthagiri AR, Torner JC, Medel R, Jane JA, Jr., et al. Intraoperative ultrasound guidance for the placement of permanent ventricular cerebrospinal fluid shunt catheters: a single-center historical cohort study. World neurosurgery. 2014;81 2:397-403; doi: 10.1016/j.wneu.2013.01.039.

15. Reig AS, Stevenson CB, Tulipan NB. CT-based, fiducial-free frameless stereotaxy for difficult ventriculoperitoneal shunt insertion: experience in 26 consecutive patients. Stereotactic and functional neurosurgery. 2010;88 2:75-80; doi:

$10.1159 / 000271822$.

16. Nesvick CL, Khan NR, Mehta GU, Klimo P, Jr. Image Guidance in Ventricular Cerebrospinal Fluid Shunt Catheter Placement: A Systematic Review and Meta-Analysis. Neurosurgery. 2015;77 3:321-31; discussion 31; doi:

Page 9/18 
17. Yim B, Reid Gooch M, Dalfino JC, Adamo MA, Kenning TJ. Optimizing ventriculoperitoneal shunt placement in the treatment of idiopathic intracranial hypertension: an analysis of neuroendoscopy, frameless stereotaxy, and intraoperative CT. Neurosurgical focus. 2016;40 3:E12; doi: 10.3171/2015.12.FOCUS15583.

18. Peraio S, Amen MM, Ali NM, Zaher A, Mohamed Taha AN, Tamburrini G. Endoscopic Management of Pediatric Complex Hydrocephalus. World neurosurgery. 2018; doi: 10.1016/j.wneu.2018.07.187.

19. Deopujari CE, Padayachy L, Azmi A, Figaji A, Samantray SK. Neuroendoscopy for post-infective hydrocephalus in children. Child's nervous system : ChNS : official journal of the International Society for Pediatric Neurosurgery. 2018;34 10:1905-14; doi: 10.1007/s00381-018-3901-z.

20. Flannery AM, Duhaime AC, Tamber MS, Kemp J. Pediatric hydrocephalus: systematic literature review and evidencebased guidelines. Part 3: Endoscopic computer-assisted electromagnetic navigation and ultrasonography as technical adjuvants for shunt placement. J Neurosurg-Pediatr. 2014;14:24-9; doi: 10.3171/2014.7.Peds14323.

21. Yamada S, Ishikawa M, Yamamoto K. Utility of Preoperative Simulation for Ventricular Catheter Placement via a Parieto-Occipital Approach in Normal-Pressure Hydrocephalus. Operative neurosurgery. 2018; doi: 10.1093/ons/opy193.

22. Nimsky C, Ganslandt O, Cerny S, Hastreiter P, Greiner G, Fahlbusch R. Quantification of, visualization of, and compensation for brain shift using intraoperative magnetic resonance imaging. Neurosurgery. 2000;47 5:1070-9; discussion 9-80.

23. Wilson TJ, Stetler WR, Al-Holou WN, Sullivan SE. Comparison of the accuracy of ventricular catheter placement using freehand placement, ultrasonic guidance, and stereotactic neuronavigation Clinical article. Journal of neurosurgery. 2013;119 1:66-70; doi: 10.3171/2012.11.Jns111384.

24. Sato O, Yamguchi T, Kittaka M, Toyama H. Hydrocephalus and epilepsy. Child's nervous system : ChNS : official journal of the International Society for Pediatric Neurosurgery. 2001;17 1-2:76-86.

25. Larsson J, Israelsson H, Eklund A, Malm J. Epilepsy, headache, and abdominal pain after shunt surgery for idiopathic normal pressure hydrocephalus: the INPH-CRasH study. Journal of neurosurgery. 2018;128 6:1674-83; doi: 10.3171/2017.3.JNS162453.

26. Karimy JK, Zhang J, Kurland DB, Theriault BC, Duran D, Stokum JA, et al. Inflammation-dependent cerebrospinal fluid hypersecretion by the choroid plexus epithelium in posthemorrhagic hydrocephalus. Nature medicine. 2017;23 8:9971003; doi: 10.1038/nm.4361.

27. Benveniste RJ, Sur S. Delayed symptom progression after ventriculoperitoneal shunt placement for normal pressure hydrocephalus. Journal of the neurological sciences. 2018;393:105-9; doi: 10.1016/j.jns.2018.08.002.

28. Stieglitz LH, Giordano M, Samii M, Luedemann WO. A New Tool for Frameless Stereotactic Placement of Ventricular Catheters. Neurosurgery. 2010;67 3:131-5; doi: 10.1227/01.Neu.0000382964.72262.9a.

29. Paff M, Alexandru-Abrams D, Muhonen M, Loudon W. Ventriculoperitoneal shunt complications: A review. Interdisciplinary Neurosurgery. 2018;13:66-70; doi: 10.1016/j.inat.2018.04.004.

30. Dickerman RD, McConathy WJ, Morgan J, Stevens QE, Jolley JT, Schneider S, et al. Failure rate of frontal versus parietal approaches for proximal catheter placement in ventriculoperitoneal shunts: revisited. Journal of clinical 
neuroscience : official journal of the Neurosurgical Society of Australasia. 2005;12 7:781-3; doi:

10.1016/j.jocn.2004.12.005.

\section{Tables}

Table 1 The outcome evaluation system

Outcome evaluation system

Severity of hydrocephalus symptoms grading system

\begin{tabular}{llll} 
Grade & Gait disturbance & Urinary incontinence & Cognitive impairment \\
\hline 0 & Normal & Normal & Normal \\
\hline 1 & $\begin{array}{l}\text { Cautious gait or impaired tandem } \\
\text { gait }\end{array}$ & $\begin{array}{l}\text { Sporadic } \\
\text { incontinence or urge } \\
\text { phenomenon }\end{array}$ & $\begin{array}{l}\text { Minimal attentional or } \\
\text { memory deficits }\end{array}$ \\
\hline 2 & Considerable unstable gait & $\begin{array}{l}\text { Frequent } \\
\text { incontinence }\end{array}$ & $\begin{array}{l}\text { Considerable deficits, but } \\
\text { oriented to situative } \\
\text { context }\end{array}$ \\
\hline 3 & Unaided gait not possible & $\begin{array}{l}\text { No or only minimal } \\
\text { control }\end{array}$ & $\begin{array}{l}\text { Not or only marginally } \\
\text { oriented }\end{array}$ \\
\hline
\end{tabular}

\section{Placement of ventricular catheter grading system}

\section{Grade}

1

Optimal position free-floating in

CSF

2 Touching choroid or ventricular wall or not in the target ventricular

3

Catheter tip terminates in parenchyma

CSF: cerebrospinal fluid

Table 2 Comparison of the clinical data between navigation and conventional surgery groups 


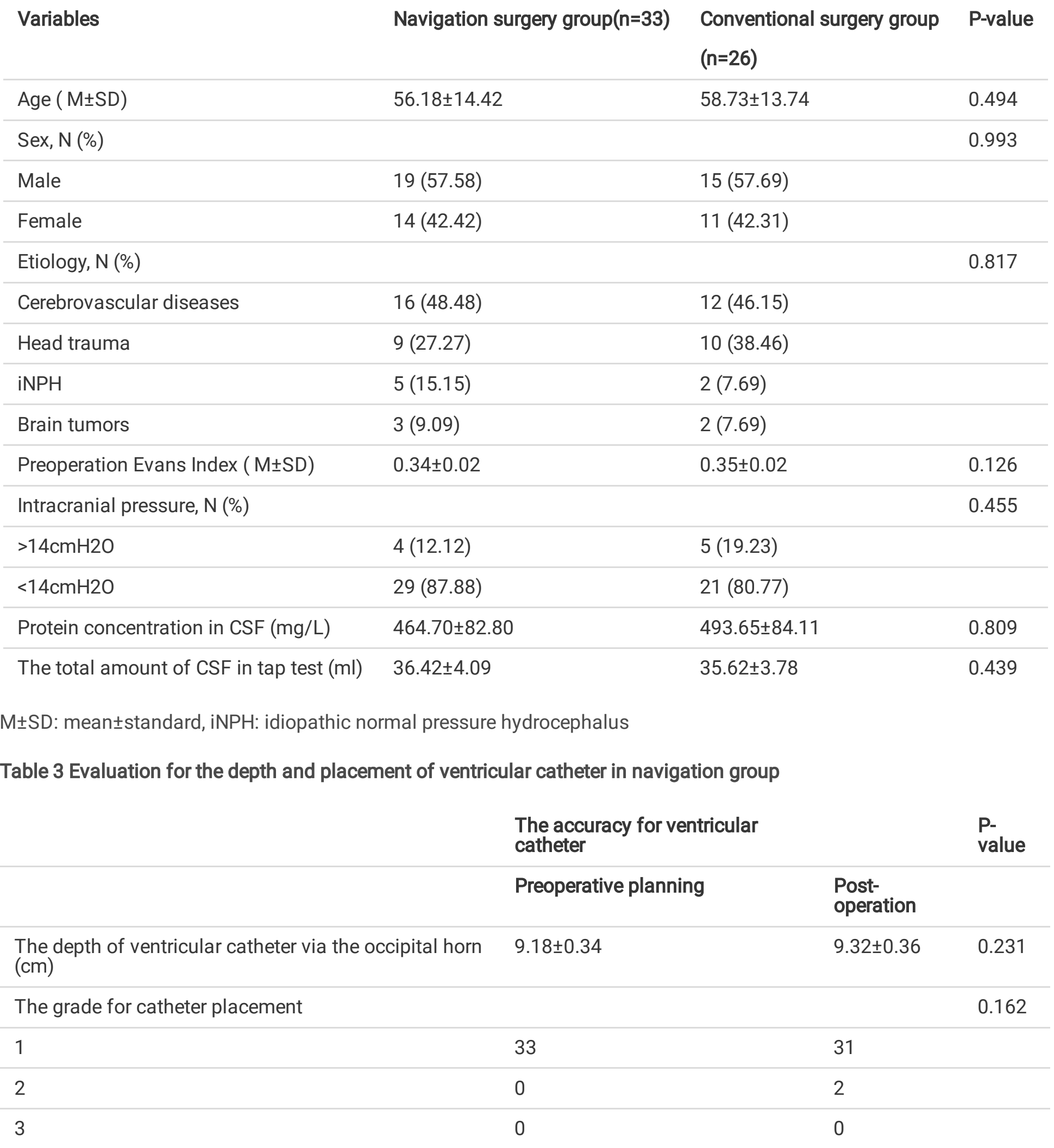

Table 4 Comparison of preoperative and postoperative symptom grade in each group 


\begin{tabular}{|c|c|c|c|c|c|c|c|c|c|}
\hline & $\begin{array}{l}\text { Navigation } \\
\text { surgery } \\
\text { group } \\
(n=33)\end{array}$ & & & & $\begin{array}{l}\text { Conventional } \\
\text { surgery } \\
\text { group } \\
(n=26)\end{array}$ & & & & $\begin{array}{l}\mathrm{P} \text { - } \\
\text { value }\end{array}$ \\
\hline $\begin{array}{l}\text { Symptom } \\
\text { grade }\end{array}$ & 0 & 1 & 2 & 3 & 0 & 1 & 2 & 3 & \\
\hline $\begin{array}{l}\text { Preoperative } \\
\mathrm{N}(\%)\end{array}$ & 0 & $\begin{array}{l}4 \\
(12.12)\end{array}$ & $\begin{array}{l}24 \\
(72.73)\end{array}$ & $\begin{array}{l}5 \\
(15.15)\end{array}$ & 0 & $\begin{array}{l}3 \\
(11.54)\end{array}$ & $\begin{array}{l}20 \\
(76.92)\end{array}$ & $\begin{array}{l}3 \\
(11.54)\end{array}$ & 0.818 \\
\hline $\begin{array}{l}\text { Postoperative } \\
N(\%)\end{array}$ & $\begin{array}{l}4 \\
(12.12)\end{array}$ & $\begin{array}{l}18 \\
(54.55)\end{array}$ & $\begin{array}{l}8 \\
(24.24)\end{array}$ & $\begin{array}{l}3 \\
(9.09)\end{array}$ & $\begin{array}{l}1 \\
(3.85)\end{array}$ & $\begin{array}{l}8 \\
(30.77)\end{array}$ & $\begin{array}{l}12 \\
(46.15)\end{array}$ & $\begin{array}{l}5 \\
(19.23)\end{array}$ & 0.017 \\
\hline P-value & $<0.001$ & 0.096 & & & & & & & \\
\hline
\end{tabular}

Table 5 The postoperative outcomes concerning VPS between navigation and conventional surgery groups

\begin{tabular}{|c|c|c|c|}
\hline Variables & Navigation surgery group $(n=33)$ & $\begin{array}{l}\text { Conventional surgery group } \\
(n=26)\end{array}$ & P-value \\
\hline Operative time $(\mathrm{min}),(\mathrm{M} \pm \mathrm{SD})$ & $64.00 \pm 5.86$ & $77.77 \pm 7.38$ & $<0.001$ \\
\hline Postoperative Evans Index ( $\mathrm{M} \pm \mathrm{SD}$ ) & $0.26 \pm 0.04$ & $0.29 \pm 0.03$ & $<0.001$ \\
\hline Blockage of the catheter, $\mathrm{N}(\%)$ & $3(9.09)$ & $9(34.62)$ & $<0.001$ \\
\hline Infection & 0 & 1 & 0.264 \\
\hline $\begin{array}{l}\text { Catheter adjusted, } \\
\mathrm{N}(\%)\end{array}$ & $3(9.09)$ & $9(34.62)$ & $<0.001$ \\
\hline Bleeding & 0 & 1 & 0.264 \\
\hline Follow-up time (months), ( $\mathrm{M} \pm \mathrm{SD}$ ) & $19.15 \pm 8.41$ & $18.46 \pm 8.78$ & 0.760 \\
\hline
\end{tabular}

Table 6 The correlation analysis between catheter placement and catheter obstruction

\begin{tabular}{lll} 
Variables & Pearson Coefficients & P-value \\
\hline Catheter placement & 0.740 & $<0.001$ \\
\hline Catheter obstruction & &
\end{tabular}

Table 7 The characteristics of obstruction of ventricular catheter cases in the 2 groups 


$\begin{array}{lllllll}\begin{array}{l}\text { Number of } \\ \text { cases }\end{array} & \text { Gender } & \text { Age } & \text { etiology } & \begin{array}{l}\text { Symptom } \\ \text { grade }\end{array} & \begin{array}{l}\text { Grade of ventricular } \\ \text { catheter placement }\end{array} & \begin{array}{l}\text { Puncture } \\ \text { fime to } \\ \text { frequency }\end{array} \\ \text { failure } \\ \text { (months) }\end{array}$

Navigation

surgery group

\begin{tabular}{llllllll}
\hline 1 & M & 68 & Head trauma & 2 & 2 & 1 & 26 \\
\hline 2 & M & 61 & $\begin{array}{l}\text { Cerebrovascular } \\
\text { diseases }\end{array}$ & 3 & 1 & 1 & 35 \\
\hline 3 & F & 53 & $\begin{array}{l}\text { Cerebrovascular } \\
\text { diseases }\end{array}$ & 3 & 2 & 1 & 32
\end{tabular}

Conventional surgery group

\begin{tabular}{llllllll}
\hline 1 & F & 45 & Head trauma & 3 & 3 & 1 & 5 \\
\hline 2 & M & 73 & $\begin{array}{l}\text { Cerebrovascular } \\
\text { diseases }\end{array}$ & 3 & 2 & 1 & 18 \\
\hline 3 & M & 68 & $\begin{array}{l}\text { Cerebrovascular } \\
\text { disease }\end{array}$ & 3 & 2 & 1 & 17 \\
\hline 4 & $\mathrm{~F}$ & 57 & Head trauma & 2 & 1 & 1 & 22 \\
\hline 5 & $\mathrm{M}$ & 72 & $\begin{array}{l}\text { Cerebrovascular } \\
\text { diseases }\end{array}$ & 2 & 3 & 1 & 4 \\
\hline 6 & $\mathrm{M}$ & 49 & Head trauma & 2 & 3 & 1 & 6 \\
\hline 7 & $\mathrm{~F}$ & 57 & $\begin{array}{l}\text { Cerebrovascular } \\
\text { diseases }\end{array}$ & 2 & 3 & 3 & 1 \\
\hline 8 & $\mathrm{M}$ & 61 & $\begin{array}{l}\text { Cerebrovascular } \\
\text { diseases }\end{array}$ & 2 & 3 & 1 & 8 \\
\hline 9 & $\mathrm{M}$ & 54 & Head trauma & 2 & 3 & 2 & 9
\end{tabular}

Table 8 Survival distribution between navigation and conventional surgery groups

Overall comparisons

\begin{tabular}{llll} 
& $\chi 2$ & Degree of freedom & P-value \\
\hline Log Rank(Mantel-Cox) & 4.828 & 1 & 0.028 \\
\hline Breslow(Generalized Wilcoxon) & 8.640 & 1 & 0.003 \\
\hline Tarone-Ware & 8.051 & 1 & 0.005
\end{tabular}

\section{Figures}




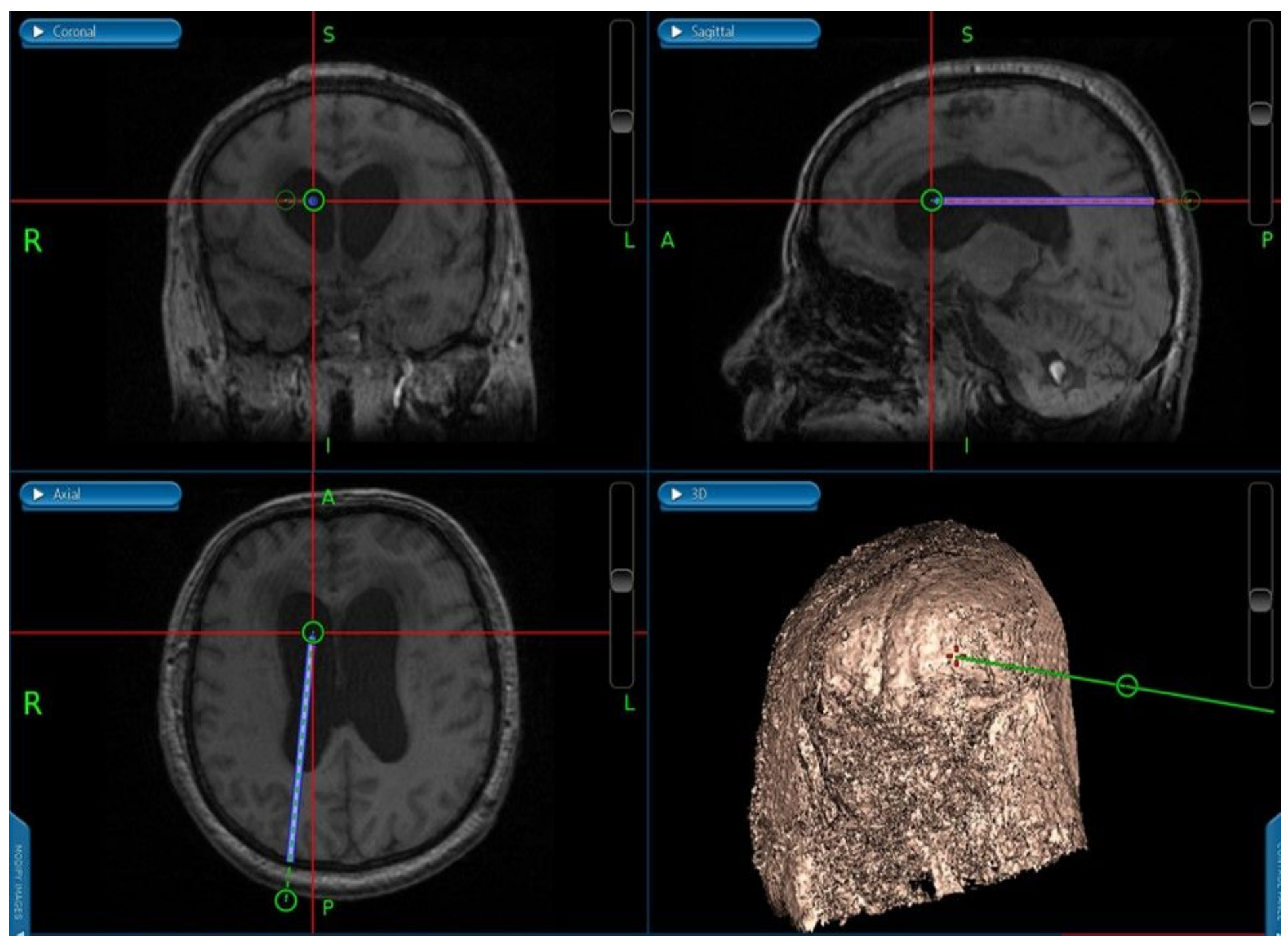

\section{Figure 1}

This was a preoparative planning picture for one patient with hydrocephalus in navigation system This was coronal, sagittal, axial and 3D imaging. The green circle in ventricle was the target point, while another green circle in picture $\mathrm{c}$ was the entry point. The blue line was trajectory. 


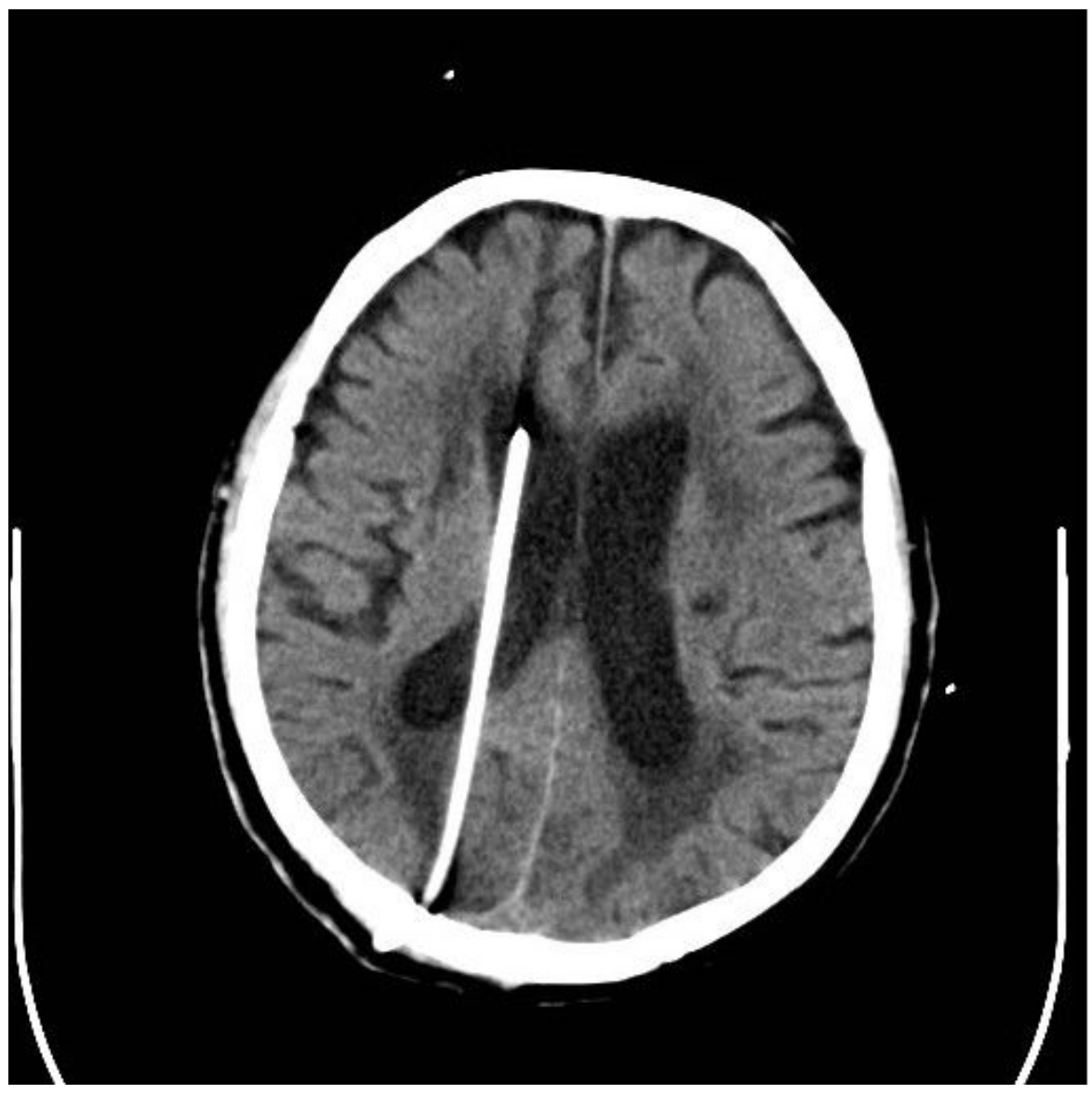

Figure 2

CT scan was for one patient with VPS during the 1st day after surgery It showed the ventricular catheter tip was in the target zone (grade 1).

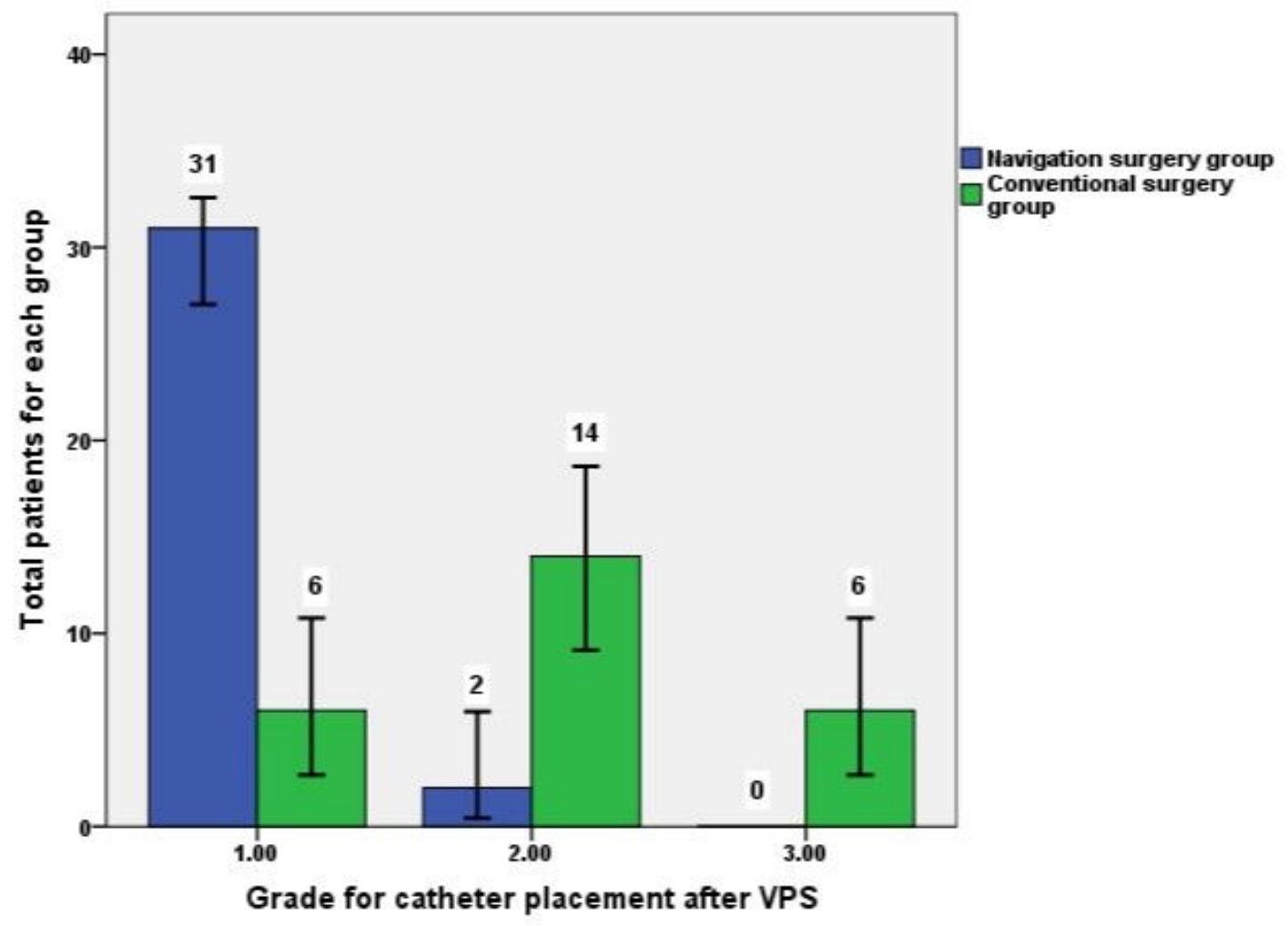


Figure 3

The total patients in each grade for catheter placement after VPS between these 2 groups.

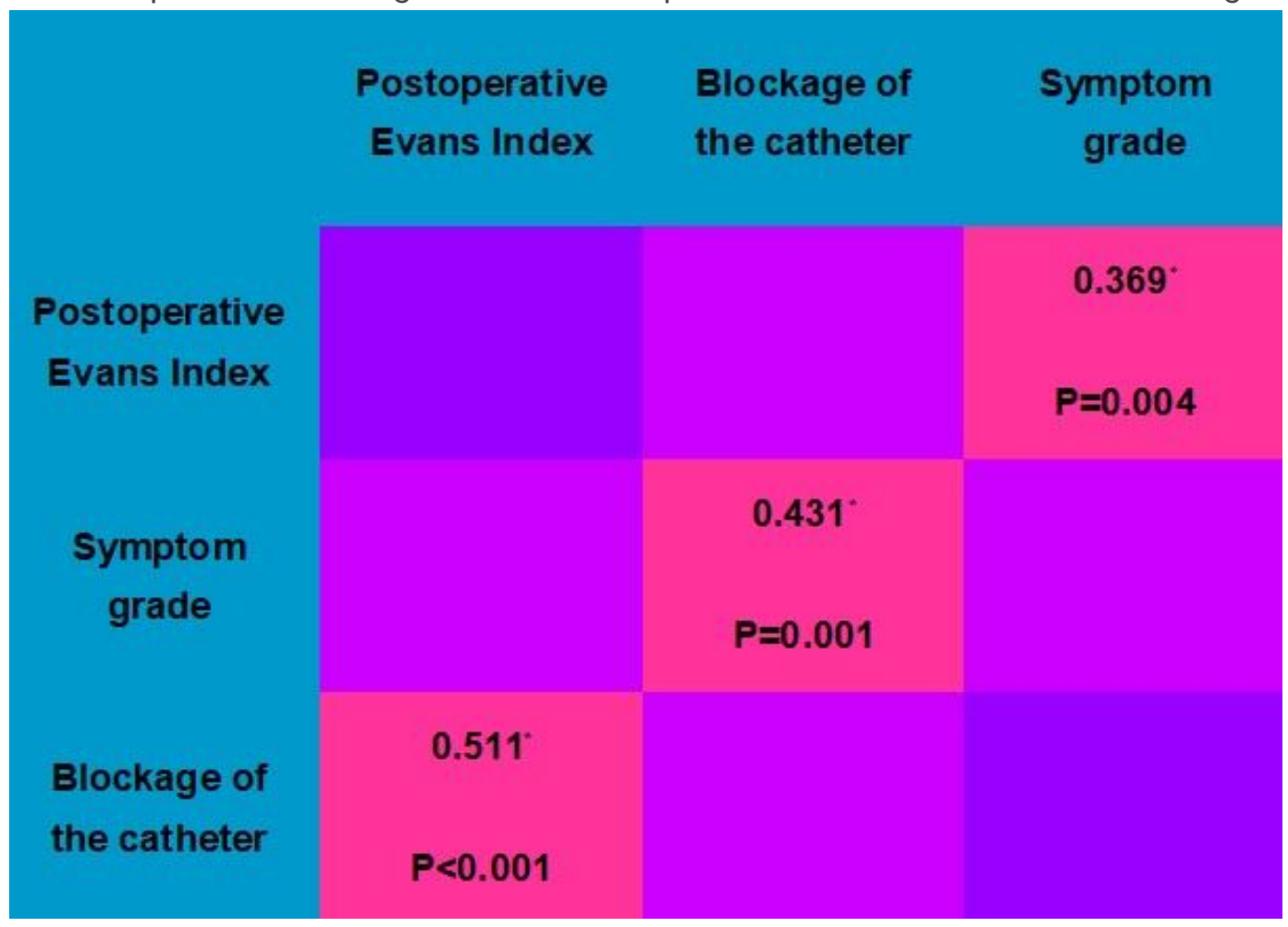

\section{Figure 4}

The correlations of catheter obstruction with symptom grade and postoperative Evans index. *: Pearson coefficient

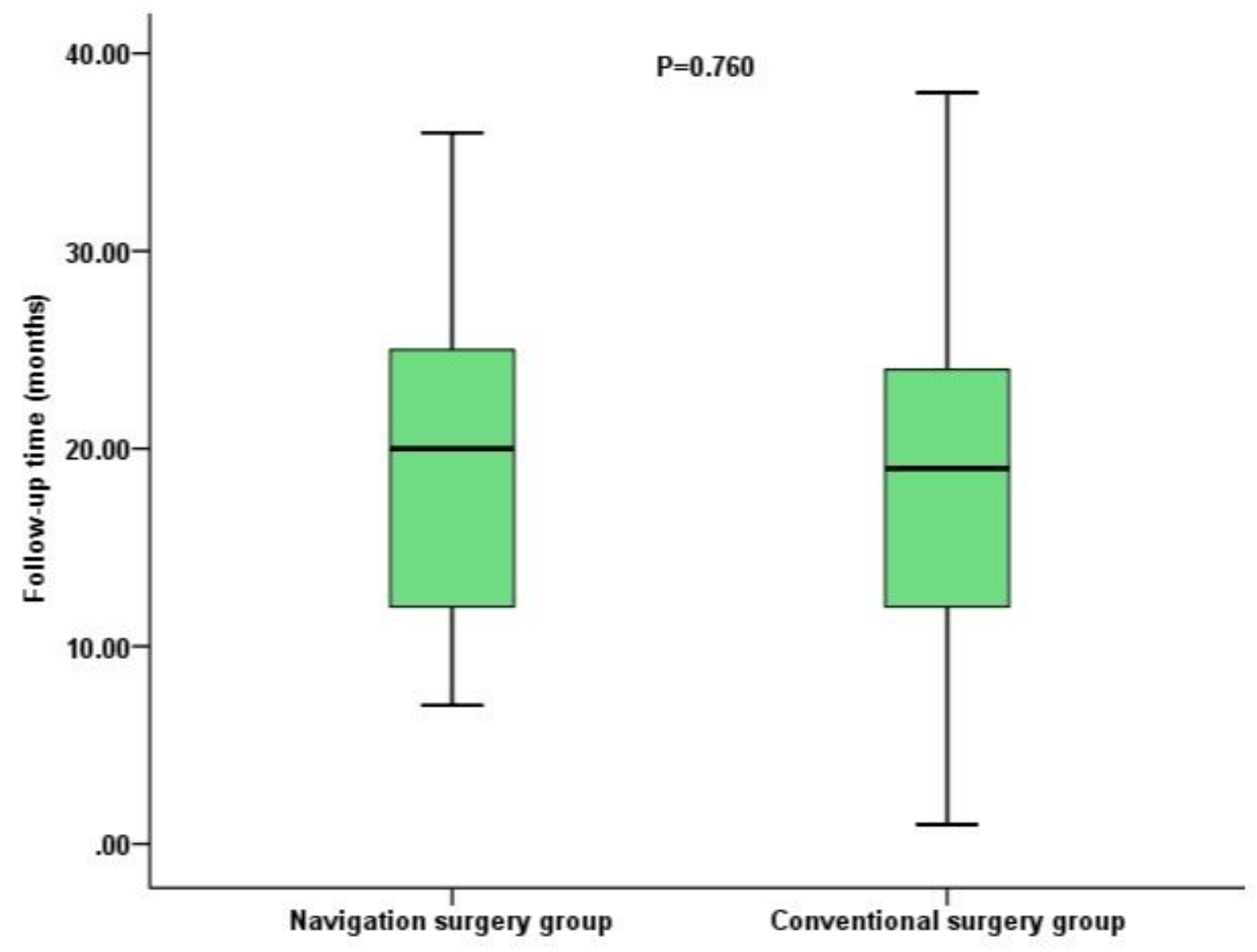




\section{Figure 5}

The Box-plot of follow-up time for these 2 groups.

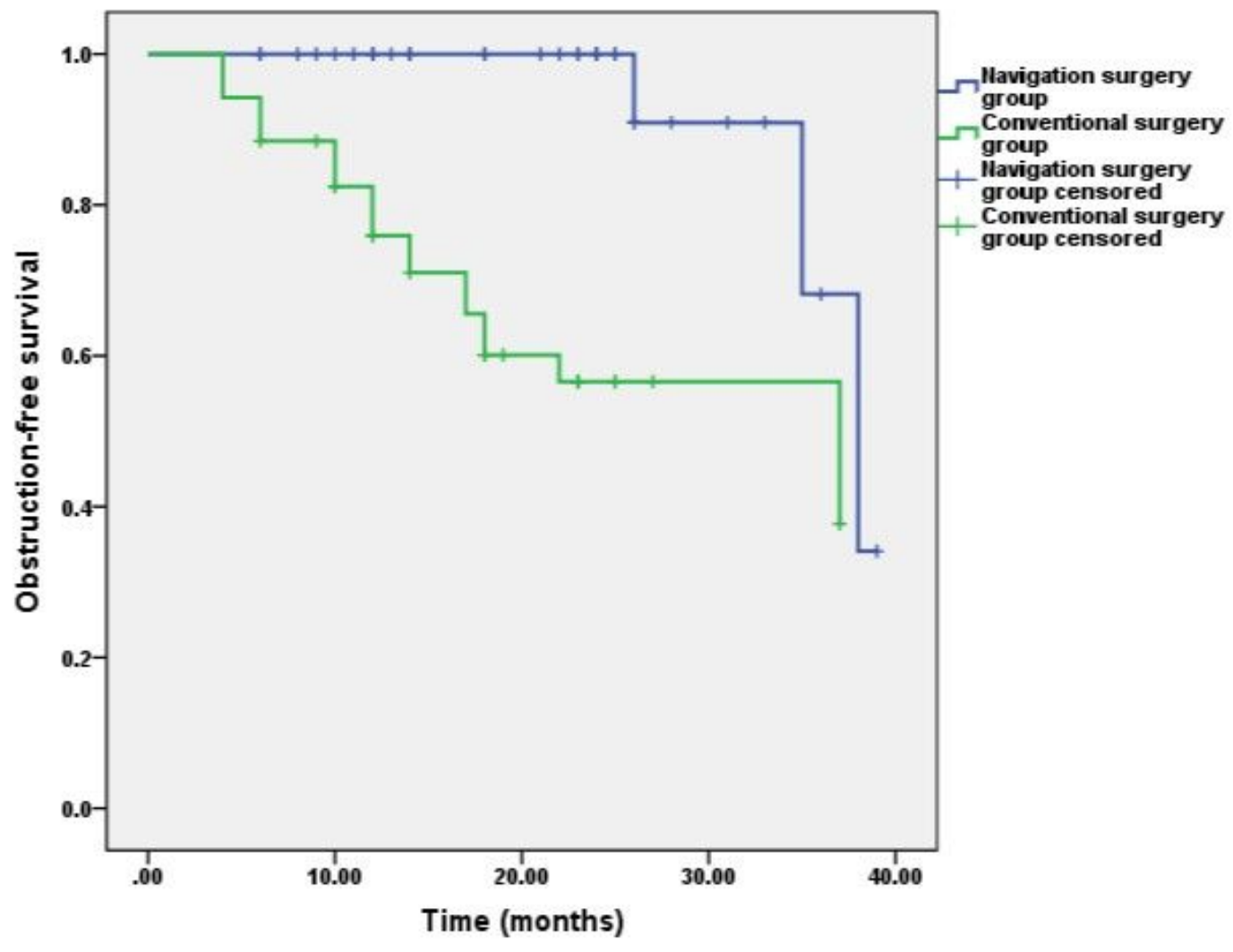

Figure 6

The Kaplan-Meier curve of the cumulative survival time between navigation and conventional surgery groups. 